\title{
SEVERE LEFT VENTRICULAR DYSFUNCTION IN FALCIPARUM MALARIA: A CASE REPORT AND REVIEW OF LITERATURE ON CARDIAC INVOLVEMENT IN MALARIA
}

\author{
Chaudhary N. ${ }^{1}$, Verma N. ${ }^{2}$, Bhatia B.D. ${ }^{3}$, Gupta B.K. ${ }^{4}$, Kabiraj N., , Lodha R. ${ }^{6}$
}

\section{INTRODUCTION}

Malaria is an important cause of death in both children and adults, especially in tropical countries like India ${ }^{1 .}$ Nearly one third cases of malaria are reported from South Asia where majority (65\%) of them are from India alone ${ }^{1,2}$. If undiagnosed and untreated promptly, falciparum malaria can be an important cause for high case fatality rate. Cerebral malaria is one of the commonest causes of death in children ${ }^{1}$. Although involvement of myocardium and cardiac failure is rare, few cases have been reported in literature. We report a 10-year old male child diagnosed as falciparum malaria with severe left ventricular dysfunction.

\section{CASE SCENARIO}

A 10 year old male child, a resident of Bihar (malaria endemic zone) was referred to our tertiary care hospital (All India Institute of Medical Sciences, New Delhi, India) with complaints of high grade fever associated with chills and rigors for 10 days. He had history of non projectile, non bilious vomiting two days back and two episodes of loose watery stool on the day of admission. There was no history of cough, rapid breathing, haematuria, bleeding from any sites, jaundice, altered sensorium, joint pains, haematuria or oliguria. Two days prior to admission, he had received packed red cell transfusion outside in view of anemia. On admission, child presented with shock, tachypnea, tachycardia and severe pallor but was conscious and responding well to commands. He had hepatomegaly with no palpable spleen. On investigation, he had anemia (Hb-7.5 gm/dl), thrombocytopenia (Platelet count: 10,000), deranged renal parameters (urea/creatinine: 64/1.4), prolonged prothombin time (12/23), no dyselectrolytemia, normal liver function tests (bilirubin -0.5, SGOT-38, SGPT-29, ALP-156). Malarial antigen test was positive for falciparum malaria. Malarial parasite quantitative buffy count (MP-QBC) was positive for P. falciparum with parasite count of $120,000 / \mu \mathrm{L}$. Child received fluid boluses and ionotropic support (dopamine infusion). Child had clinical features suggestive of heart failure and 2D- echocardiography was done which was suggestive of severe left ventricular dysfunction (ejection fraction: 20\%), global hypokinesia with collapsing IVC. Child was treated with IV artesunate and Clindamycin for 7 days. He was also started on milrinone infusion for 3 days. Broad spectrum antimicrobials were also added with the possibility of associated sepsis. He required one packed red cell transfusion and multiple platelet concentrate transfusions. Child also was put on non invasive CPAP for 3 days to reduce the work of breathing. DIC profile was positive. Chest X-ray was normal and cultures were sterile. Serial P. falciparum parasite count was done which showed improvement serially and was zero at day 8 of therapy. Repeat ECHO showed improvement of left ventricular ejection fraction (LVEF-40\%).

1. Assistant Professor, Department of Paediatrics, Universal college of Medical Sciences \& Teaching Hospital, Bhairahawa, Nepal

2. Senior Resident, Department of Paediatrics, All India Institute of Medical Sciences, New Delhi, India

3. Head Department of Paediatrics, Universal college of Medical Sciences \& Teaching Hospital, Bhairahawa, Nepal

4. Assistant Professor, Department of Paediatrics, Universal college of Medical Sciences \& Teaching Hospital, Bhairahawa, Nepal

5. Post Graduate Resident, Department of Paediatrics, Universal college of Medical Sciences \& Teaching Hospital, Bhairahawa, Nepal

6. Associate Professor, Department of Paediatrics, All India Institute of Medical Sciences, New Delhi, India

\author{
For Correspondence \\ Dr. Nagendra Chaudhary, M.D., \\ Assistant Professor, \\ Department of Paediatrics, \\ Universal College of Medical Sciences \& Teaching Hospital, \\ Bhairahawa, Nepal \\ E-mail: cnagendra@hotmail.com
}


Table 1: Values of various laboratory parameters

\begin{tabular}{|l|l|l|l|l|l|}
\hline Parameters & Reference values & Day 1 & Day 2 & Day 4 & Day 8 \\
\hline Hemoglobin (g/dL) & $12.5-16.9$ & 7.5 & 11.3 & 8 & 10.3 \\
\hline PLT & $110-330$ & 10,000 & 18,000 & 15,000 & 95,000 \\
\hline WBC & $3.5-11.0$ & 4900 & 6000 & 6500 & 6000 \\
\hline Creatinine (mg/dL) & $<1.3$ & 1.4 & 0.7 & 0.6 & 0.5 \\
\hline Urea (mg/dl) & & 64 & 41 & 24 & 25 \\
\hline Glucose (mg/dL) & $60-126$ & 74 & 128 & 102 & 109 \\
\hline Sodium (mmol/L) & $135-145$ & 134 & 137 & 131 & 134 \\
\hline Calcium (mg/dL) & $8.5-10.5$ & & 7.1 & 7.1 & 8.7 \\
\hline Potassium(mmol/L) & $3.3-5.0$ & 4 & 4.5 & 3.5 & 4 \\
\hline Chloride (mmol/L) & $95-110$ & 116 & 115 & 107 & 112 \\
\hline Phosphate & & & 1.7 & 2.8 & 4.7 \\
\hline AST (lUlL) & $<37$ & 95 & 38 & 52 \\
\hline ALT (lUlL) & $<53$ & & 41 & 29 & 38 \\
\hline Total bilirubin (mg/dL) & $0.3-1.5$ & & 156 & 0.4 & 0.5 \\
\hline Alkaline Phosphatase & & & & 181 & 202 \\
\hline Creatine phosphokinase(lUlL) & $<200$ & & & 48 & \\
\hline LDH & & $12 / 23$ & $11 / 14.6$ & 5 & \\
\hline CPK MB & & 1,2 & 2 & 2 & \\
\hline PT (seconds) & $11.0-13.5$ & & & No \\
\hline Transfusion (PRBC-1, PRP-2) & & & & \\
\hline
\end{tabular}

\section{DISCUSSION}

Falciparum malaria is one of the commonest cause for causing severe malaria. Severe malaria is characterized by involvement of one ore more of the following: Severe anemia, impaired consciousness or unarousable coma, metabolic acidosis, jaundice, acute kidney injury, increased lactate, hypoglycemia, respiratory distress with pulmonary edema and with hyperparasitemia. ${ }^{1}$ Cardiac failure in malaria is probably due to impaired tissue perfusion resulting in hypoxemia and metabolic acidosis. Cardiac involvement is rarely noticed and left ventricular function is preserved even in severe disease. ${ }^{1,-5}$ If involved, has a high case fatality rate (Table 2). Table 2 below depicts cases of $\mathrm{P}$. falciparum malaria causing cardiac dysfunction. Case fatality rate of more than $60 \%$ has been noticed.

Table 2: Comparision of cases with cardiac involvement and its outcome

\begin{tabular}{|l|l|l|l|}
\hline References & Cases & Diagnosis & Outcomes \\
\hline Kumar et al (6) & 2 & $\begin{array}{l}\text { Acute heart failure } \\
\text { ventricular fibrillation }\end{array}$ & $\begin{array}{l}\text { Cure } \\
\text { Death }\end{array}$ \\
\hline Costenaro et al (7) & 1 & Myocarditis & Death \\
\hline Wennicke et al (8) & 1 & Acute heart failure & Death \\
\hline Wichmann et al (9) & 2 & $\begin{array}{l}\text { Myocarditis } \\
\text { Unknown }\end{array}$ & $\begin{array}{l}\text { Death } \\
\text { Death }\end{array}$ \\
\hline Tripathy et al. (10) & 1 & Myocarditis & N/A \\
\hline Mohsen et al (11) & 1 & Myocarditis & cure \\
\hline Present case & 1 & Acute Left Heart failure & Cure \\
\hline
\end{tabular}

In the past, the antimalarial quinine was thought to be cardiotoxic which caused arrhythmias and hypotension, but evidence available suggests that at therapeutic doses, it has no adverse effects on cardiac conduction or function. ${ }^{3,12}$

In a recent study done by Kathrin Wennicke et al in vitro and in mice suggest that the Glycosylphosphatidylinositol (GPI) purified from Plasmodium falciparum has a important role in the pathogenesis of malaria and could be responsible for cardiomyocyte apoptosis. ${ }^{8}$ Severe and complicated malaria has been associated with myocardial injury, reversible global hypokinesia and diffuse myocardial necrosis diagnosed by raised troponin-T, echocardiography and autopsy findings. ${ }^{13}$ Circulating concentrations of cardiac proteins have been demonstrated in patients with both complicated and uncomplicated P. falciparum malaria. ${ }^{14}$ In a study in Ghana, where cases were diagnosed clinically and based on positive blood smears, regardless of the severity of the infection, myocardial damage demonstrated by cardiac troponin T (cTnT) was rare. ${ }^{5}$ In our case also cardiac enzymes (CPK-MB, 
LDH) were normal despite the severity in Left ventricular dysfunction, suggesting the poor sensitivity of cardiac enzymes in malaria induced heart failure. Mocumbi et al studied 47 children and concluded that myocardial damage and dysfunction are rare in severe and complicated Plasmodium falciparum malaria. ${ }^{15}$ Tripathy et al. found one case of myocarditis in a series of 1682 severe malaria children. ${ }^{10}$ In a case reported from UK by Mohsen et al in a 30 year old female with Worst EF of 35\% having myocarditis was discharged subsequently. ${ }^{11}$ Franzen et al had reported one patient with global ventricular hypokinesia. ${ }^{16}$ In a recent case series of two patients, mortality rate of $50 \%$ was demonstrated by Kumar et $\mathrm{al}^{6}$. Yacoub et al demonstrated that children with severe malaria and metabolic acidosis have evidence of intravascular volume depletion and associated cardiac dysfunction. ${ }^{17}$

Cardiac involvement in malaria requires early diagnosis and treatment measures to reduce the case fatality rate. Clinical diagnosis added by echocardiography helps in diagnosis. Use of fluid therapy, ionotropes, blood components and Artemisinin Combination Therapy (ACT) helps in a favorable outcome.

\section{REFERENCES}

1. World Health Organization (WHO), Guidelines for the Treatment of Malaria, World HealthOrganization, Geneva, Switzerland, 2nd edition, 2010.

2. Snow RW, Guerra CA, Noor AM, Myint HY, Hay SI. The global distribution of clinical episodes of Plasmodium falciparum malaria. Nature. 2005 Mar 10;434(7030):2147.

3. Bethell DB, Phuong PT, Phuong CX, Nosten F, Waller D, Davis TM et al. Electrocardiographic monitoring in severe falciparum malaria. Trans. R. Soc. Trop. Med. Hyg. 1996 Jun;90(3):2669.

4. Bruneel F, Hocqueloux L, Alberti C, Wolff M, Chevret S, Bédos JP et al. The clinical spectrum of severe imported falciparum malaria in the intensive care unit: report of 188 cases in adults. Am. J. Respir. Crit. Care Med. 2003 Mar 1;167(5):6849.

5. Günther A, Grobusch MP, Slevogt H, Abel W, Burchard GD. Myocardial damage in falciparum malaria detectable by cardiac troponin T is rare. Trop. Med. Int. Health. 2003 Jan;8(1):302.

6. Kumar PP, Kumar CD, Shaik FAR, Ghanta SB. Myocardial dysfunction in severe falciparum malaria. J. Trop. Pediatr. 2010 Feb;56(1):678.

7. Costenaro P, Benedetti P, Facchin C, Mengoli C, Pellizzer G. Fatal Myocarditis in Course of Plasmodium falciparum
Infection: Case Report and Review of Cardiac Complications in Malaria. Case Report Med. 2011;2011:202083.

8. Wennicke K, Debierre GF, Wichmann D, Brattig NW, Pankuweit S, Maisch B et al. Glycosylphosphatidylinositolinduced cardiac myocyte death might contribute to the fatal outcome of Plasmodium falciparum malaria. Apoptosis. 2008 Jul;13(7):85766.

9. Wichmann $O$, Löscher T, Jelinek T. Fatal malaria in a German couple returning from Burkina Faso. Infection. 2003 Aug;31(4):2602.

10. Tripathy R, Parida S, Das L, Mishra DP, Tripathy D, Das $M C$, et al. Clinical manifestations and predictors of severe malaria in Indian children. Pediatrics. 2007 Sep;120(3):e454460.

11. Mohsen AH, Green ST, West JN, McKendrick MW. Myocarditis associated with Plasmodium falciparum malaria: a case report and a review of the literature. J Travel Med. 2001 Aug;8(4):21920.

12. White NJ. Cardiotoxicity of antimalarial drugs. Lancet Infect Dis. 2007 Aug; 7(8):54958.

13. Mohapatra MK. The natural history of complicated falciparum malaria--a prospective study. J Assoc Physicians India. 2006 Nov; $54: 84853$.

14. EhrhardtS, Wichmann D, Hemmer CJ, Burchard GD, Brattig $N W$. Circulating concentrations of cardiac proteins in complicated and uncomplicated Plasmodium falciparum malaria. Trop. Med. Int. Health. 2004 Oct;9(10):1099103.

15. Mocumbi AO, Sidi D, Ferreira MB, et al. A population study of endomyocardial fibrosis in the community. New Engl $J$ Med 2008;369:439.

16. Franzen D, Curtius JM, Heitz W, Höpp HW, Diehl V, Hilger HH. Cardiac involvement during and after malaria. Clin Investig. 1992 Aug;70(8):6703.

17. Yacoub S, Lang HJ, Shebbe M, Timbwa M, Ohuma E, Tulloh $R$ et al. Cardiac function and hemodynamics in Kenyan children with severe malaria. Crit. Care Med. 2010 Mar;38(3):9405. 